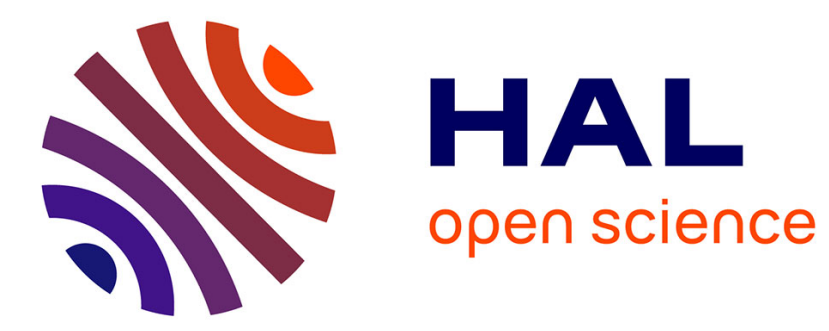

\title{
PWM Inverter-Fed Induction Motor-Based Electrical Vehicles Fault-Tolerant Control
}

Bekheira Tabbache, Mohamed Benbouzid, Abdelaziz Kheloui, Jean-Matthieu Bourgeot, Abdeslam Mamoune

\section{> To cite this version:}

Bekheira Tabbache, Mohamed Benbouzid, Abdelaziz Kheloui, Jean-Matthieu Bourgeot, Abdeslam Mamoune. PWM Inverter-Fed Induction Motor-Based Electrical Vehicles Fault-Tolerant Control. IEEE IECON 2013, Nov 2013, Vienne, Austria. pp.8204-8209. hal-00926258

\section{HAL Id: hal-00926258 https://hal.science/hal-00926258}

Submitted on 9 Jan 2014

HAL is a multi-disciplinary open access archive for the deposit and dissemination of scientific research documents, whether they are published or not. The documents may come from teaching and research institutions in France or abroad, or from public or private research centers.
L'archive ouverte pluridisciplinaire HAL, est destinée au dépôt et à la diffusion de documents scientifiques de niveau recherche, publiés ou non, émanant des établissements d'enseignement et de recherche français ou étrangers, des laboratoires publics ou privés. 


\title{
PWM Inverter-Fed Induction Motor-Based Electrical Vehicles Fault-Tolerant Control
}

\author{
Bekheïra Tabbache, Mohamed Benbouzid, Abdelaziz Kheloui, \\ Jean-Matthieu Bourgeot and Abdeslam Mamoune
}

\begin{abstract}
This paper proposes a fault-tolerant control scheme for PWM inverter-fed induction motor-based electric vehicles. The proposed strategy deals with power switch (IGBTs) failures mitigation within a reconfigurable induction motor control. In a vehicle context, 4-wire and 4-leg PWM inverter topologies are investigated and their performances discussed. Two topologies exploit the induction motor neutral accessibility for fault-tolerant purposes. The 4-wire topology uses then classical hysteresis controllers to account for the IGBT failures. The 4-leg topology, meanwhile, uses a specific 3D space vector PWM to handle vehicle requirements in terms of size (DC bus capacitors) and cost (IGBTs number). Experiments on an induction motor drive and simulations on an electric vehicle are carried-out using a European urban driving cycle to assess the FTC scheme performance and effectiveness.
\end{abstract}

Index Terms-Electric vehicle (EV), induction motor, inverter, fault-tolerant control (FTC), IGBT failure, hysteresis control, 3D space vector pulse width modulation (SVPWM).

\section{INTRODUCTION}

Adjustable speed AC motor drives are widely used in numerous critical industrial, manufacturing, and transportation applications. This has therefore escalated the importance of developing fault-tolerant capabilities for such systems. In particular, voltage source inverters are a key component of these electric motor drive systems.

It is estimated that about $38 \%$ of the faults in variable-speed ac drives in industry are due to failures of power devices [1-3]. Most of these inverters use insulated IGBTs as the power device. This percentage will be higher if control circuit failures are taken into account. They may consist of faults such as inverter intermittent misfiring due to defects in control circuit elements or electromagnetic interference that results in gate-drive open faults, and consequently leads to IGBT open-circuit.

Although IGBTs are rugged, they suffer failures due to excess electrical and thermal stress that are experienced in harsh environments such in automotive applications. IGBT failures can be broadly categorized as open-circuit faults, short-circuit faults, and intermittent gate-misfiring faults [2].

In the automotive context, the dependence of an electric vehicle on the variable-speed ac drives and particularly on the power inverter is rapidly increasing the concern over fault tolerance due to availability issues [4-7].

B. Tabbache and A. Kheloui are with the Ecole Militaire Polytechnique, 16111 Algiers, Algeria.

M.E.H. Benbouzid and A. Mamoune are with the University of Brest, EA 4325 LBMS, Rue de Kergoat, CS 93837, 29238 Brest Cedex 03, France (email: Mohamed.Benbouzid@univ-brest.fr).

J.M. Bourgeot is with the ENIB, EA 4325 LBMS, 945, Avenue Technopole, 29280 Plouzané, France.
Figure 1 summarizes potential faults that could afflict a power inverter. Two common types of power converter faults that were investigated are transistor gate-drive open fault or IGBT open-circuit switch fault $\left(\mathrm{F}_{3}\right)$, and IGBT short-circuit switch fault $\left(\mathrm{F}_{4}\right)$, as depicted in Fig. 1. These two faults can lead to catastrophic failures of the drive or to significantly degraded performances. It is therefore crucial to detect and diagnose these two faults so as to take the appropriate remedial action to mitigate the fault effects [2], [8-11]. Faults a priori knowledge is assumed in this paper and the focus will be on the remedial actions upon fault occurrence.

Once the fault is detected and located remedial actions should be carried-out to mitigate the fault effects. Several power inverter architecture based on some hardware redundancy have been suggested to add reconfigurability to the system. For induction motor drives, these solutions propose two main trends: 1) Modify the standard $\mathrm{DC}-\mathrm{AC}, \mathrm{AC}-\mathrm{DC}-\mathrm{AC}$ or $\mathrm{AC}-\mathrm{AC}$ topologies by adding extra bidirectional switches to bypass the faulty IGBT or short-circuited windings, and using the motor neutral connection. 2) Include redundant power devices in the actuator hardware topology that can be switched on or off in the case of an IGBT failure [12]. In an analytical point of view, the references to generate the post-fault switching patterns have to be modified to properly excite the motor under the resulting topology. Therefore, if hardware redundancy and post-fault well-adapted control are efficiently combined, very effective hardware reconfiguration schemes could be designed. This is one of the main bases of the proposed FTC approaches.

In this context, a survey of different fault-tolerant structures is provided in [12]. For automotive applications (electric vehicles), the focus will be on classical and mature inverter structure (Fig. 3). In this context, [3] and [13-14] give an overview of the existing solutions along with their merits and drawbacks.

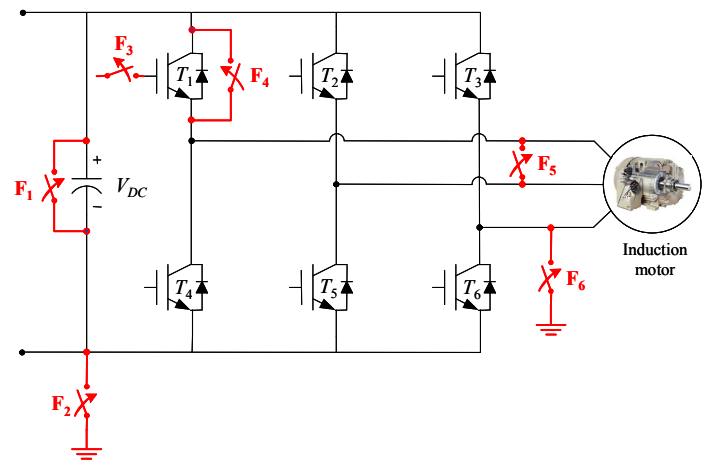

Fig. 1. Potential inverter faults. 
In this context, the primary focus of this paper is to propose PWM inverter fault-tolerant topologies and to develop lowcost adaptive control mitigation strategies within the specific context of an electric vehicle. The primary objective is to propose fault-tolerant topologies that require only minimum hardware modifications. To increase the vehicle powertrain reliability regarding IGBT open-circuit failures, 4-wire and 4leg PWM inverter topologies are investigated and their performances discussed in a vehicle context.

\section{4-WIRE PWM INVERTER FAULT-TOLERANT CONTROL}

The investigated topology is illustrated by Fig. 2. It has been previously proposed in [15]. It is based on modifying the post-fault control strategy with the connection of the motor neutral to the mid-point of the split DC bus capacitor link of the drive. This topology is capable of mitigating both IGBT open-circuit and short-circuits faults. It uses a conventional three-phase drive with the addition of four triacs and three fast acting fuses (isolation switches) connected in series with the motor. The motor neutral is connected to the split DC link midpoint through $T R_{n}$ (connection switch). The three other triacs and the fuses are used for fault isolation purposes [3].

All triacs are turned-off in healthy operation. During postfault operation, the faulty leg is isolated and the drive operates therefore in a two-phase mode with its neutral connected to the split DC link mid-point (by turning-on TRn).

\section{A. Control Reconfiguration}

Fault-tolerant control in an EV context requires maintaining the propulsion motor at its rated performance with the same load torque. In this case and for an open circuit failure in phase $\boldsymbol{b}$, the remaining healthy phase currents should controlled to a magnitude of $\sqrt{ } 3$ times of their value in healthy conditions and phase-shifted by $(\pi / 6)$ forward for the $\boldsymbol{a}$-phase current and by $(\pi / 6)$ backward for the $c$-phase current (Fig. 3). Post-fault currents can therefore be expressed by

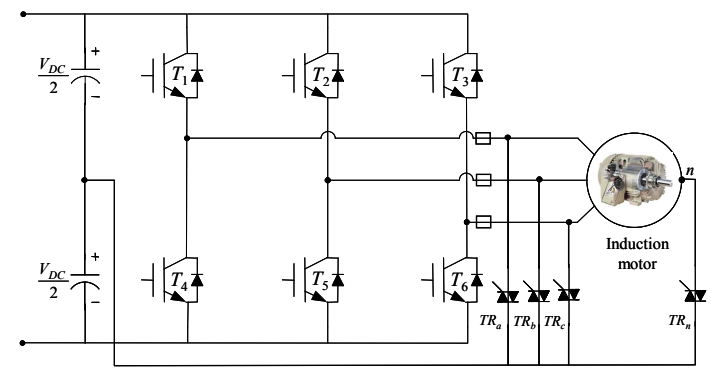

Fig. 2. 4-wire neutral-connected induction motor fault-tolerant topology.

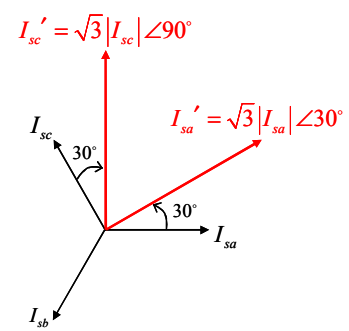

Fig. 3. Current vectors before and after an open-circuit failure in phase $\boldsymbol{b}$.
$\left\{\begin{array}{l}I_{s a}^{\prime}=\sqrt{3} I \cos \left(\omega t+\varphi+\frac{\pi}{6}\right) \\ I_{s c}^{\prime}=\sqrt{3} I \cos \left(\omega t+\varphi+\frac{\pi}{2}\right)\end{array}\right.$

Figure 4 illustrates FTC principle in event of an opencircuit in IGBT $T_{2}$ or $T_{5}$. In this case, the faulty leg is isolated by a specific switch (i.e. fast-acting fuse).

\section{B. FTC Experimental Tests}

1) Test bench. The test bench used to validate the proposed active fault-tolerant control approach is made up of a $1-\mathrm{kW}$ induction motor drive whose ratings are given in the Appendix. The experimental test bench main measurement and control components are: an absolute encoder attached to the motor shaft, Hall effect current and voltage sensors, and a dSPACE 1102 development board which is interfaced to a standard PC.

Experiments are therefore carried-out to test the above described induction motor 2-phase control. In this case, an open-circuit failure is introduced in phase $\boldsymbol{b}$.

2) Experimental results. Figures 5 to 7 show the FTC performance after the fault occurrence. It is therefore obvious that the induction motor torque and speed remain stable with quasi no fluctuations in presence of an inverter failure thanks to the FTC strategy.

3) What about EV applications? This fault-tolerant topology has a first main drawback which is the neutral accessibility in the particular case of a delta-connected induction motor. For an EV application a first drawback would be the propulsion motor overrating to withstand the increased currents in the healthy phases. Moreover, as the neutral current is no longer zero, this causes voltage fluctuations. A larger size DC capacitor is then required to minimize the voltage ripple and sustain the desired voltage level (Fig. 8). However, using larger size DC capacitor will increase the propulsion system size and therefore its cost. Improvements are therefore needed, in terms of topology and control, to cope with these last drawbacks.

\section{4-LEG 3D SVPWM INVERTER FAULT-TOLERANT CONTROL}

Fault tolerance for an induction motor drive can be accomplished by adding an extra inverter leg to a standard three-phase voltage source inverter configuration [16]. The extra leg is connected to the induction motor neutral which requires a star-connected machine with an available neutral.

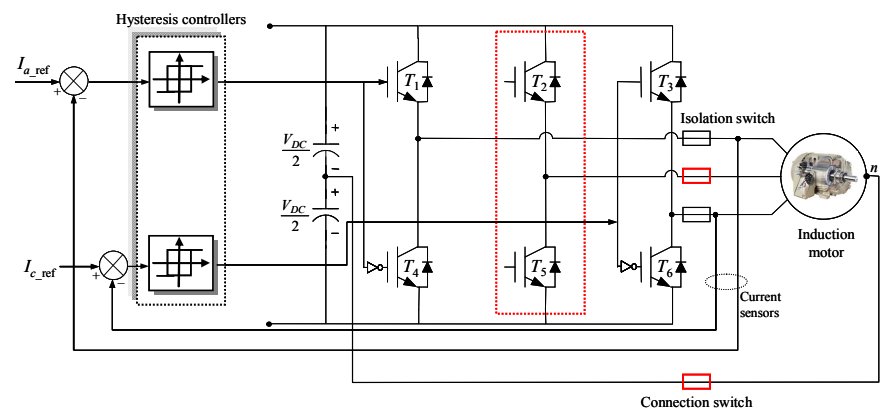

Fig. 4. FTC strategy scheme with a neutral-connected induction motor. 


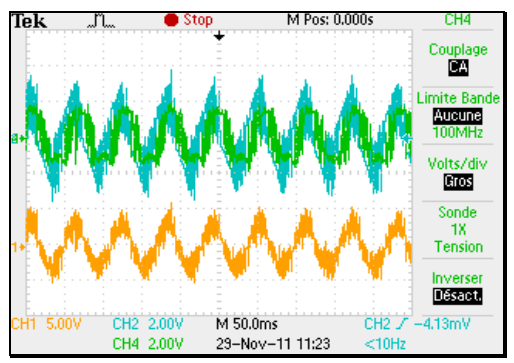

Fig. 5. Induction motor stator currents (lower curve is neutral current).

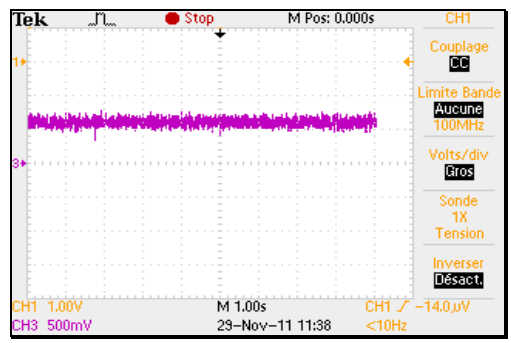

Fig. 6. Induction motor torque.

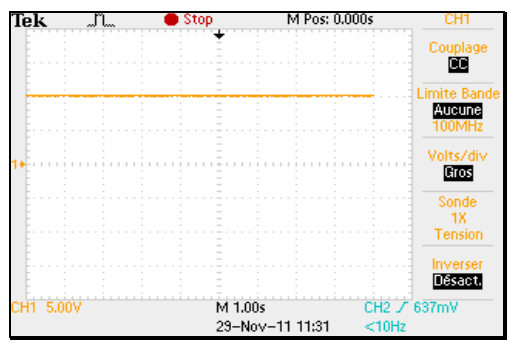

Fig. 7. Induction motor speed.

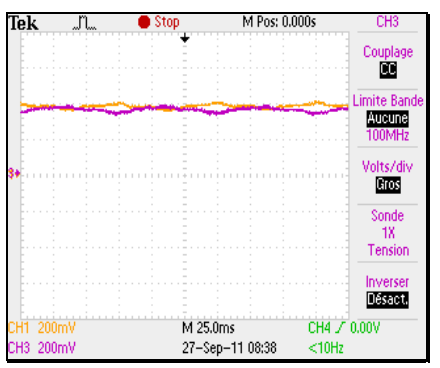

(a) Capacitors of $4700 \mu \mathrm{F}$.

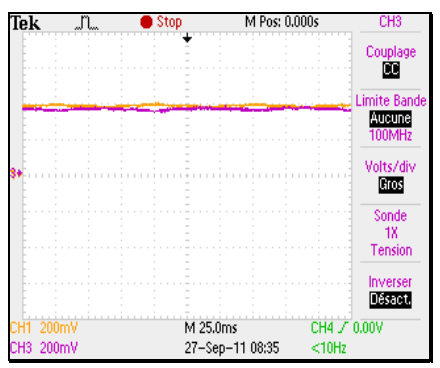

(b) Capacitors of $9400 \mu \mathrm{F}$.
Fig. 8. The two DC bus voltages $V_{D C} / 2$.

The considered fault-tolerant inverter configuration considered is shown in Fig. 9.

This new structure control will consist in modifying the control references taking into account the induction motor neutral current.

In terms of control, to improve the induction motor drive performances in case of IGBT failure, it is now proposed an inverter FTC approach using a 3D SVPWM [17]. Indeed, it has been shown that 3D SVPWM achieves the full utilization of an inverter capability such as maximum output voltage at a given DC link voltage and minimum output harmonics current at given a switching frequency. Moreover, it has the ability to minimize switching and conduction losses.

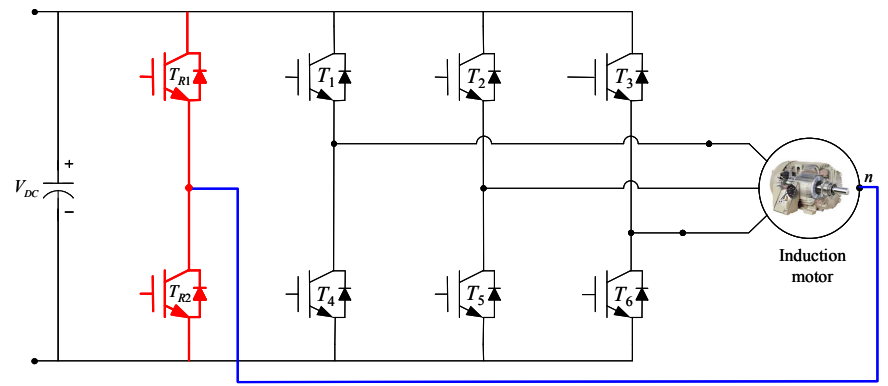

Fig. 9. 4-leg inverter neutral-connected induction motor fault-tolerant topology.

\section{A. Control Reconfiguration}

For 4-leg inverter fault-tolerant control, the 3D SVPWM technique using offset voltage has been adopted [19]. This technique needs voltage references that are generated according to the PI control scheme illustrated by Fig. 10.

\section{B. FTC Experimental Tests}

The FTC performances of the 4-leg inverter are experimentally evaluated on the same test bench.

Figure 11 illustrates the induction motor current before and after an open-circuit failure in phase $\boldsymbol{b}$ (purple waveform). After the IGBT open-circuit, the motor neutral is connected to the fourth leg through a specific device.

Figures 12 and 13 show the induction motor dynamic performances (the green line gives the inverter condition: healthy (0) then faulty (1)). It can be seen that the post-fault torque and speed have some ripple but with good tracking performances. In particular, the speed exhibits a small transient before reaching its reference. These results confirm the effectiveness of the 3D SVPWM for 4-leg inverters using the offset voltage concept.

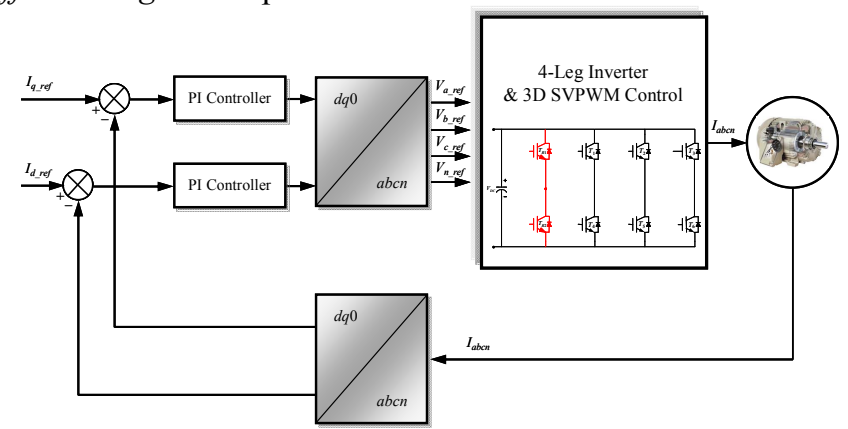

Fig. 10. 4-leg fault-tolerant control using 3D SVPWM.

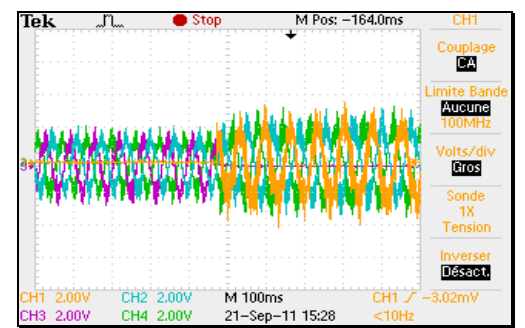

Fig. 11. Induction motor currents in healthy and faulty conditions (orange curve is the neutral current). 


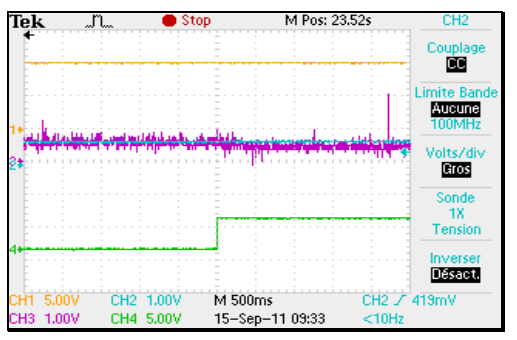

Fig. 12. Induction motor torque in healthy and fault conditions: Reference (blue) and actual torque (purple).

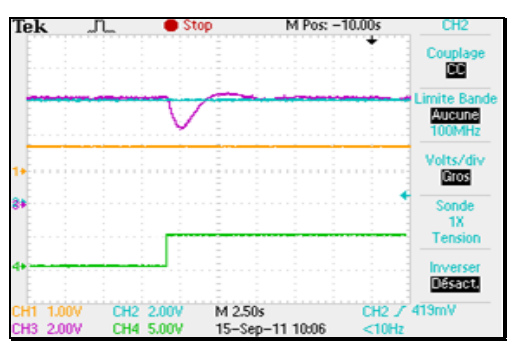

Fig. 13. Induction motor speed in healthy and fault conditions: Reference (blue) and actual speed (purple).

\section{3D SVPWM 4-LEG INVERTER-FED INDUCTION MOTOR- BASED ELECTRIC VEHICle FAULT-TOLERANT CONTROL}

In order to evaluate the proposed fault-tolerant control strategy performances, simulations have been carried-out on an electric vehicle using a $37-\mathrm{kW}$ induction motor based powertrain (Fig. 14). The EV and the used cage induction motor rated data and parameters are given in the Appendix.

To evaluate the EV dynamic performances under IGBT failure and recovery, a series of tests in different load conditions were performed to emulate different type of traction behavior of an EV. For that purpose, a European urban driving cycle is used as the speed reference (Fig. 15). In this case, an open-circuit failure and recovery in the IGBT $T_{2}$ are introduced between $20 \rightarrow 75$-sec and $150 \rightarrow 195$-sec.

Figures 16 and 17 illustrate the EV induction motor dynamic performances (speed and torque). Figure 16 clearly show that the proposed fault-tolerant approach allows the induction motor to quite perfectly track the vehicle assigned driving cycle with quite smooth transients in event of IGBT failure and recovery. Moreover, Fig. 17 shows that the EV induction motor torque is as large as are the variations of the accelerator pedal and the road profile as is not affected by the IGBT failure and recovery.

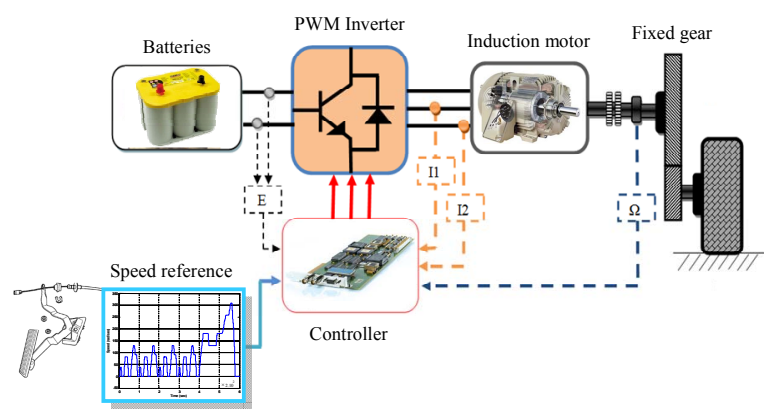

Fig. 14. EVs powertrain.

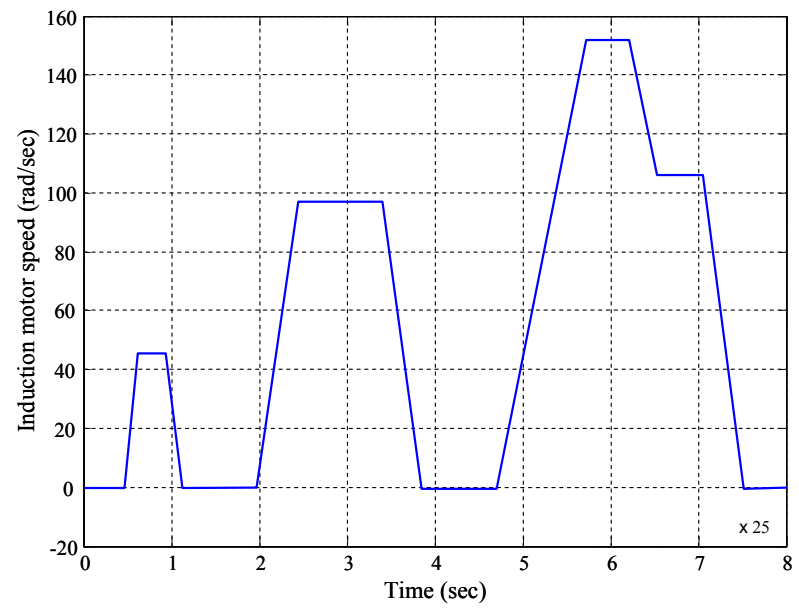

Fig. 15. EV induction motor speed (European urban driving cycle).

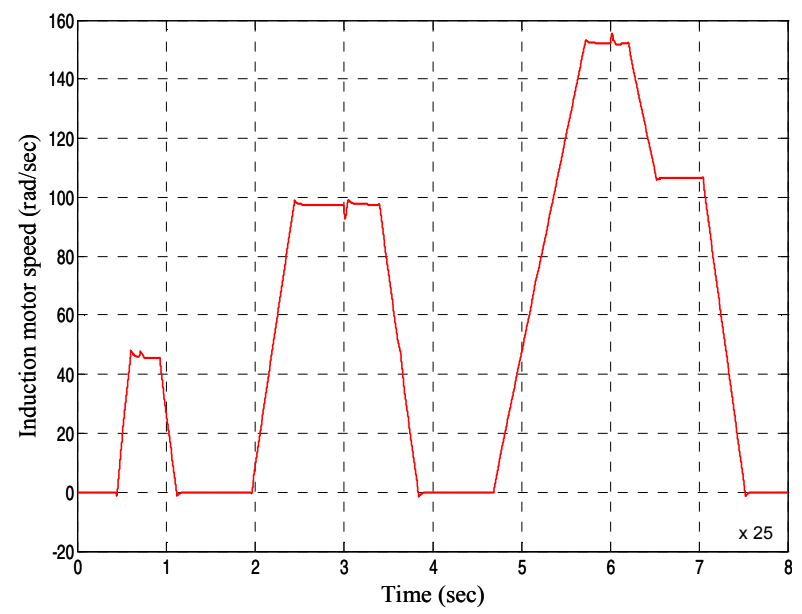

Fig. 16. EV induction motor speed.

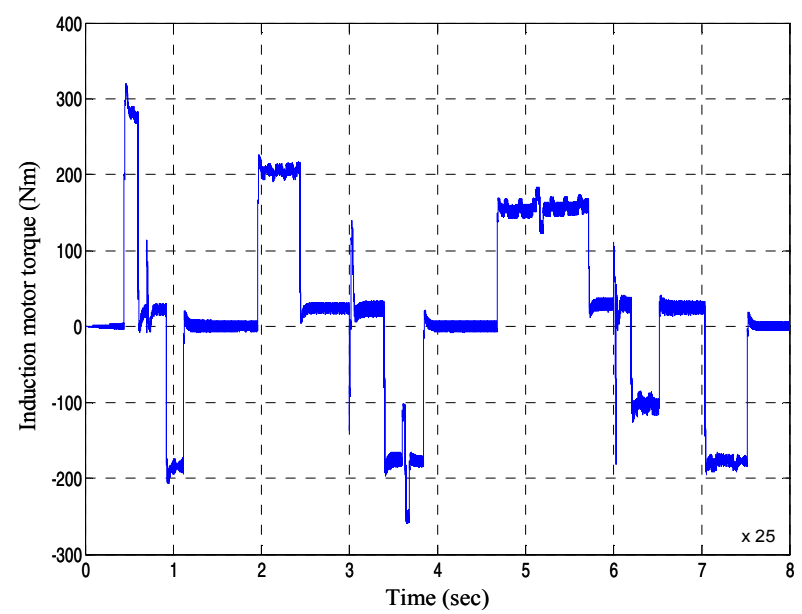

Fig. 17. EV induction motor torque.

For illustration, Fig. 18 shows the induction motor currents in both conditions. It should be noted that the motor absorbs sinusoidal currents in both conditions. Moreover, in event of a faulty IGBT, it should be mentioned that the fundamental rms current amplitudes in the motor phases are increased by a $\sqrt{3}$ factor only if rated performances are required. 


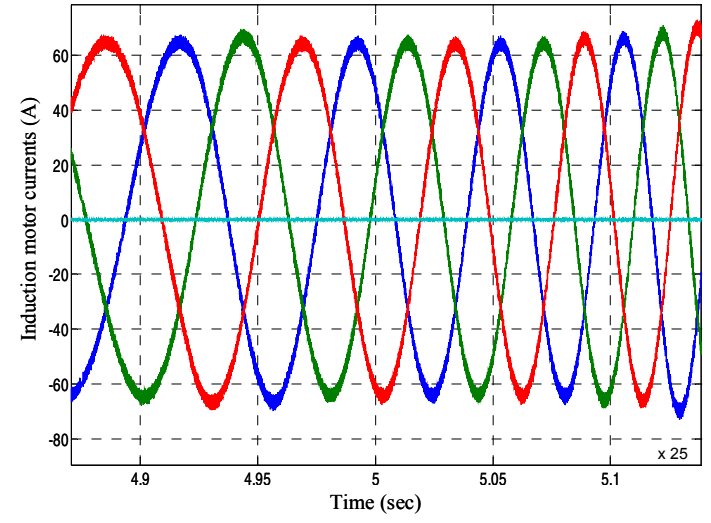

(a) Healthy conditions.

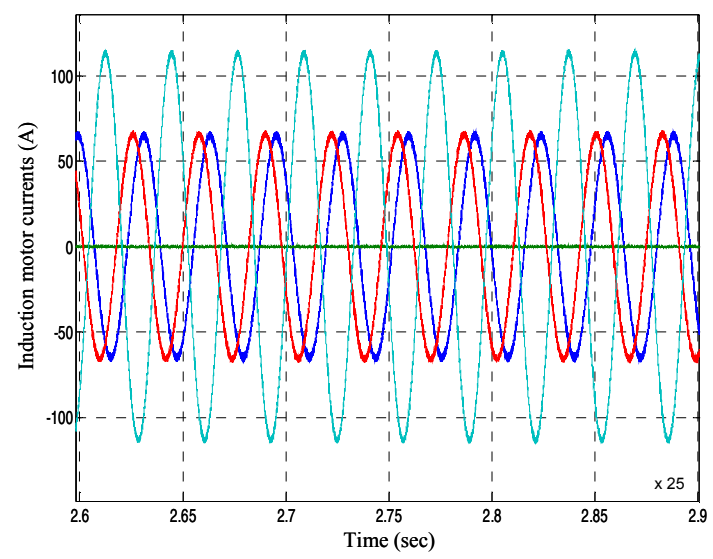

(b) IGBT $T_{2}$ failure.

Fig. 18. EV induction motor currents (cyan curve is the neutral current).

This will not be the case for the entire driving cycle as shown by Fig. $18 b$.

\section{CONCLUSIONS}

Two inverter fault-tolerant topologies have been investigated. Both topologies exploit the induction motor neutral accessibility for fault-tolerant purposes.

The first one is based on a classical three-phase inverter with the motor neutral connected to the DC bus mid-point. The achieved performances are unfortunately poor in terms of control mainly due to the hysteresis controllers and in terms of voltage ripples. In this case, a larger size DC capacitor is required to minimize the voltage ripple and sustain the desired voltage level. This is unfortunately not acceptable for EVs applications. To cope with these drawbacks, the 4-leg inverter topology has been adopted as a key candidate where the redundant leg is connected to the motor neutral. The main features of the proposed inverter fault-tolerant topology are the following:

- No access to the DC bus mid-point (use of one DC capacitor).

- The control adopts a 3D SVPWM technique using the offset voltage concept.

- The pre-fault induction motor performances are maintained in post-fault operation. In an EV context and according to driving cycle tests, this a key feature that allow the vehicle to perfectly track cycle requirements. This has been confirmed by the induction motor-based EV simulations results in terms of dynamic performances. However, if the application requires rated post-fault power, then the phase current increases by $\sqrt{3}$ factor. It should be mentioned in this case that for an EV application, the rated power is not continuously required (driving cycle).

- In [19], it has been suggested that the neutral leg topology is one of the two promising ones for various inverter faults and in particular for automotive applications. However, the simplified additional phase leg topology with mechanical relays was found to be the most cost effective and fault-tolerant. The proposed fault-tolerant approach has nevertheless brought critical improvements to the neutral leg topology over the phase leg one. Indeed, it is now possible to obtain rated torque during post-fault operation with no additional torque ripples thanks to the adopted 3D SVPWM.

The carried-out experiments on an induction motor drive and simulations on an electric vehicle using a European urban driving cycle clearly show that the proposed 3D SVPWM neutral leg inverter fault-tolerant control approach is effective and provides a simple configuration with high performance in terms of speed and torque responses.

\section{APPENDIX}

EV MEChaniCAL AND AEROdYNAMIC PARAMETERS

$$
\begin{gathered}
m=1540 \mathrm{~kg} \text { (two } 70 \mathrm{~kg} \text { passengers), } A=1.8 \mathrm{~m}^{2}, r=0.3 \mathrm{~m} \\
\mu_{r r 1}=0.0055, \mu_{r r 2}=0.056, C_{a d}=0.19, G=3.29, \eta_{g}=0.95 \\
v_{0}=4.155 \mathrm{~m} / \mathrm{sec}, g=9.81 \mathrm{~m} / \mathrm{sec}^{2}, \rho=0.23 \mathrm{~kg} / \mathrm{m}^{3}
\end{gathered}
$$

\begin{tabular}{|c|}
\hline $\begin{array}{c}37 \mathrm{~kW}, 1480 \mathrm{rpm}, p=2 \\
R_{s}=0.0851 \Omega, R_{r}=0.0658 \Omega \\
L_{s}=0.0314 \mathrm{H}, L_{r}=0.0291 \mathrm{H}, L_{m}=0.0291 \mathrm{H}, \\
J=0.37 \mathrm{~kg} . \mathrm{m}^{2}, k_{f}=0.02791 \mathrm{Nmsec}\end{array}$ \\
\hline RATED DATA OF THE TESTED INDUCTION MOTOR \\
\hline $\begin{array}{c}1 \mathrm{~kW}, 2.5 \mathrm{Nm}, 2830 \mathrm{rpm}, p=1 \\
R_{s}=4.750 \Omega, R_{r}=8.000 \Omega, L_{s}=0.375 \mathrm{H}, L_{r}=0.375 \mathrm{H}, L_{m}=0.364 \mathrm{H} \\
J=0.003 \mathrm{~kg} \cdot \mathrm{m}^{2}, k_{f}=0.0024 \mathrm{Nmsec}\end{array}$ \\
\hline
\end{tabular}

RATED DATA OF THE SiMUlated INDUCTION MOTOR

\section{REFERENCES}

[1] R.R. Errabelli and P. Mutschler, “ Fault-tolerant voltage source inverter for permanent magnet drives," IEEE Trans. Power Electronics, vol. 27, n², pp. 500-508, February 2012.

[2] B. Lu and S.K. Sharma, "A literature review of IGBT fault diagnostic and protection methods for power inverters," IEEE Trans. Industry Applications, vol. 45, n5, pp. 1770-1777, September/October 2009.

[3] C.C. Yeh and N.A.O. Demerdesh, "Induction motor-drive systems with fault tolerant inverter-motor capabilities," in Proceedings of the 2007 IEEE IEMDC, Antalya (Turkey), vol. 2, pp. 1451-1458, May 2007.

[4] B. Tabbache, M.E.H. Benbouzid, A. Kheloui and J.M. Bourgeot, "Virtual sensor-based maximum likelihood voting approach for fault-tolerant control of electric vehicle powertrains," IEEE Trans. Vehicular Technology, vol. 62, n³, pp. 1075-1083, March 2013. 
[5] J.H. Hu, D. Yin and Y. Hori, "Fault-tolerant traction control of electric vehicles," Control Engineering Practice, vol. 19, n², pp. 204-213, February 2011.

[6] B. Akin, S.B. Ozturk, H.A. Toliyat and M. Rayner, "DSP-based sensorless electric motor fault-diagnosis tools for electric and hybrid electric vehicle powertrain applications," IEEE Trans. Vehicular Technology, vol. 58, n6, pp. 2679-2688, July 2009.

[7] M.E.H. Benbouzid, D. Diallo and M. Zeraoulia, "Advanced fault-toleran control of induction-motor drives for EV/HEV traction applications: From conventional to modern and intelligent control techniques," IEEE Trans. Vehicular Technology, vol. 56, n², pp. 519-528, March 2007.

[8] M.E.H. Benbouzid, C. Delpha, Z. Khatir, S. Lefebvre and D. Diallo, Faults Detection and Diagnosis in a Static Converter, Electrical Machines Diagnosis, Chap. 9, p. 271-316, ISBN: 978-1-84821-263-3, Wiley, ISTE, Paris 2011.

[9] D.U. Campos-Delgado and D.R. Espinoza-Trejo, "An observer-based diagnosis scheme for single and simultaneous open-switch faults in induction motor drives," IEEE Trans. Industrial Electronics, vol. 58, n² pp. 671-679, February 2011.

[10] Q.T. An, L.Z. Sun, K. Zhao and L. Sun, "Switching function modelbased fast-diagnostic method of open-switch faults in inverters without sensors," IEEE Trans. Power Electronics, vol. 26, n²1, pp. 119-126, January 2011

[11] F. Zidani, D. Diallo, M.E.H. Benbouzid and R. Naït Saïd, “A fuzzy-based approach for the diagnosis of fault modes in a voltage-fed PWM inverter induction motor drive," IEEE Trans. Industrial Electronics, vol. 55, n², pp. 586-596, February 2008.
[12] D.U. Campos-Delgado, D.R. Espinoza-Trejo and E. Palacios, "Faulttolerant control in variable speed drives: a survey," IET Electric Power Applications, vol.2, n², pp. 121-134, March 2008.

[13] A.M.S. Mendes and A.J.M. Cardoso, "Fault-tolerant operating strategies applied to three-phase induction-motor drives," IEEE Trans. Industrial Electronics, vol. 53, n6, pp. 1807-1817, December 2006.

[14] B. A. Welchko, T. A. Lipo, T. M. Jahns, and S. E. Schulz, "Fault tolerant three-phase ac motor drive topologies: A comparison of features, cost, and limitations," IEEE Trans. Power Electronics, vol. 19, n 4, pp. 1108 1116, July 2004.

[15] T.H. Liu J.R. Fu and T.A. Lipo, "A strategy for improving reliability of field-oriented controlled induction motor drives," IEEE Trans. Industry Applications, vol. 29, n5, pp. 910-918, September-October 1993.

[16] O. Wallmark, L. Harnefors and O. Carlson, "Control algorithms for a fault-tolerant PMSM drive," IEEE Trans. Industrial Electronics, vol. 54, n4, pp. 1973-1980, August 2012.

[17] S. Kwak, "Four-leg-based fault-tolerant matrix converter schemes based on switching function and space vector methods," IEEE Trans. Industrial Electronics, vol. 59, $\mathrm{n}^{\circ} 1$, pp. 235-243, January 2012.

[18] J.H. Kim and S.K. Sul, "A Carrier-based PWM method for three-phase four-leg voltage source converters," IEEE Trans. Power Electronics, vol. 19, n¹, pp. 66-75, January 2004.

[19] M. Naidu, S. Gopalakrishnan, and T.W. Nehl, "Fault-tolerant permanent magnet motor drive topologies for automotive x-by-wire systems," IEEE Trans. Industry Applications, vol. 46, $\mathrm{n}^{\circ} 2$, pp. 841-848, March/April 2010. 